\title{
The in vitro evaluation of statins as antimicrobials for trauma-related chronic infection
}

Ryan Patrick Trombetta ( $\nabla$ ryantrombetta@gmail.com )

US Army Institute of Surgical Research https://orcid.org/0000-0003-0479-5595

\section{Kaylie Lowak}

US Army Institute of Surgical Research

\section{Audrey Albach}

US Army Institute for Surgical Research

\section{Rebecca Lopez}

US Army Institute for Surgical Research

\section{Desiree Romano}

US Army Institute for Surgical Research

\section{Carlos Sanchez}

US Army Institute for Surgical Research Joseph Wenke

US Army Institute for Surgical Research

\section{Research article}

Keywords: statins, infection, biofilm, drug screen, trauma

Posted Date: March 3rd, 2020

DOI: https://doi.org/10.21203/rs.3.rs-15891/v1

License: (c) (1) This work is licensed under a Creative Commons Attribution 4.0 International License.

Read Full License 
The in vitro evaluation of statins as antimicrobials for trauma-related chronic infection

Ryan P Trombetta ${ }^{1, \#}$, Kaylie Lowak ${ }^{1}$, Audrey M Albach ${ }^{1}$, Rebecca A Lopez ${ }^{1}$, Desiree Romano ${ }^{1}$, Carlos J Sanchez ${ }^{1}$, Joseph C Wenke ${ }^{l}$

${ }^{1}$ Orthopedic Trauma Department

US Army Institute of Surgical Research

3698 Chambers Rd

San Antonio, TX 78234, United States

\#Corresponding Author

Ryan P Trombetta, Ph.D.

US Army Institute of Surgical Research

3698 Chambers Rd

San Antonio, TX 78234, United States

Phone: 1-609-578-0318

ryan.p.trombetta.ctr@mail.mil 
1 ABSTRACT

2 Background

3 Chronic wound infections continue to plague the U.S. healthcare system, especially in trauma scenarios.

4 Multidrug resistance and the capacity to form biofilm enables pathogens to survive clinical regimens of

5 antibiotics prompting the need to find antibiotic alternatives. In past years, the cholesterol lowering class of

6 drugs, statins, were identified to have antibacterial effects on pathogens responsible for various wound

7 infections. The objective of this study was to screen all available statins against a panel of pathogens $(S$.

8 aureus, $P$. aeruginosa, coagulase-negative staphylococcus (CoNS), E. coli, Klebsiella spp., and A. baumannii)

9 associated with wound infections and their ability to inhibit biofilm formation. A top-drug candidate was identified and further characterized to determine potential for clinical application.

\section{Results}

12 Statins were most effective against $S$. aureus and $A$. baumannii with minimum inhibitory concentrations (MIC)

13 ranging from 32 to $256 \mu \mathrm{g} / \mathrm{mL}$. Simvastatin was the only statin to show efficacy against $S$. aureus, $P$. aeruginosa, CoNS, and $A$. baumannii with a MIC of $32 \mu \mathrm{g} / \mathrm{mL}$. No statins were effective against $E$. coli and Klebsiella spp. Likewise, simvastatin had a relatively low minimum biofilm inhibition concentration (MBIC) of 8 $\mu \mathrm{g} / \mathrm{mL}$ for both $S$. aureus and CoNS. Moving forward, simvastatin was chosen as the top drug candidate due to its broad spectrum MICs and MBICs. Due to its particular potency against $S$. aureus, an in depth characterization was performed against $S$. aureus. However, further testing revealed minimal effects against established $S$. aureus biofilm and persister cells, as well as cytotoxicity against osteoblasts.

\section{Conclusion}

Among the 9 available statins, simvastatin demonstrated the highest antimicrobial potential with broadspectrum activity against $S$. aureus, $P$. aeruginosa, CoNS, and $A$. baumannii, as well as the ability to inhibit biofilm formation for $S$. aureus and CoNS. However, upon further in vitro characterization simvastatin was antimicrobial for orthopaedic-related infection.

Keywords: statins, infection, biofilm, drug screen, trauma 
Civilian and military wound infections continue to have a substantial socioeconomic burden in the United States. Approximately $34 \%$ of all patients who sustained a deployment-related injury develop a trauma-related infection in U.S. military hospitals (1). Similarly in the civilian population, an infection rate of $28 \%$ is reported for lower extremity trauma (2). These trauma-related infections are associated with a recalcitrant nature attributed to multidrug-resistance-organisms (MDROs) and the capacity to form an extracellular matrix (ECM) known as biofilm, which both increase the longevity, persistence, and costs of infection $(3,4)$. In 2014, the total Medicare spending for chronic nonhealing wounds was estimated as high as $\$ 96.8$ billion ( $\$ 28.1$ billion low-range estimate, $\$ 31.7$ billion midrange estimate; (5)). Overall, wound infections ravage US healthcare costs despite today's clinical standards.

During the incurrence of trauma- or ballistic-related wounding, the absence of antimicrobials leads to rapid colonization of resident gram-positive microbial flora, such as Staphylococcus aureus or Streptococcus pyogenes (6-8). Shortly thereafter, endogenous gram-negative bacteria, Pseudomonas aeruginosa, Klebsiella pneumoniae, and Escherichia coli, colonize the wound $48-72 \mathrm{~h}$ later (6-8). It is imperative that the correct antibiotics are administered as soon as possible in order to prevent the occurrence of infection. Management and treatment algorithms for high energy ballistic trauma follow the general framework of serial debridements (every 2-3 days), irrigation with saline, systemic antibiotics, fracture stabilization with local delivery of high dose antibiotics via polymethylmethacrylate cement beads, and negative pressure wound therapy utilizing distillation of antibiotics and/or antifungal solutions (9-13). However due to the uncontrollable medical care environment of a trauma-related scenario or an active battlefield, the immediacy and efficacy of these standards varies. Furthermore, the rise of MDROs limits susceptibility to conventional antibiotics for infection management and biofilm formation adds an additional factor of recalcitrance.

Within the past decade, observed trends of antimicrobial resistance have caused dire concern in both military and civilian medical fields. In the United States, MDROs cause at least 2 million infections, resulting in 23,000 deaths per year (14). The rapid emergence of MDROs has led the Center for Disease Control (CDC) to declare in 2013 that the human race is in the "post-antibiotic era." Further exacerbating the issue of chronic infection from drug resistance is the ability of pathogens to form biofilms. Biofilms act as an external barrier for 
subpopulations of slow-growing cells with poor metabolic activity known as persister cells (15). Persister cells alone have a reduced susceptibility to antibiotics due to their slow metabolism (16). The added confinement within the biofilm provides both a drug diffusion barrier and the ability to evade host immune response $(17,18)$.

osteomyelitis, where biofilm is formed on stabilization hardware enabling persistence of infection despite regimens of systemic and local antibiotics (19). The sessile bacteria protected within biofilm require more than a thousand times that of the conventional antibiotic concentration required to kill planktonic cells of the same strain (20-22). By this mechanism, bacteria can tolerate antibiotic regimens and then disperse from within the biofilm enabling recurrence of infection (23). Collectively, the alarming rise of MDROs and the capacity of pathogens to create subpopulations of persister cells contained within biofilms incites the necessity to determine antibiotic alternatives to adequately treat infections.

An emerging strategy to identify new antimicrobial drugs is drug repurposing. Drug repurposing identifies existing drugs that have off-label effects such as antimicrobial activity. Identified drugs can then be validated, tested, and streamlined from bench to bedside. An example of drug repositioning is the antirheumatoid arthritis drug, auranofin. In 2012, the US Food and Drug Administration (FDA) granted auranofin orphan drug status (24). Since then, it had been reidentified to have broad spectrum antimicrobial activity and has undergone clinical trials for the treatment of gastrointestinal protozoa (24). Drug repositioning reduces the development cycle of a drug from $10-17$ years to $3-12$ years and greatly cuts down associated costs (25).

Potential drugs for repositioning, specifically in the context of broad-spectrum antimicrobials, are the lipid-lowering statins used to treat high cholesterol. Statins have been found to have direct in vitro antibacterial effects on both Gram-positive and Gram-negative bacteria (26). Even more noteworthy is that statins, including simvastatin, lovastatin, rosuvastatin have shown to have antimicrobial activity against MDROs such as methicillin-resistant $S$. aureus (MRSA), vancomycin-resistant $S$. aureus (VRSA), and vancomycin-resistant enterococci (VRE) (27-32). Furthermore, simvastatin has been shown to have an effect and inhibit S. aureus and $P$. aeruginosa biofilm formation and also disrupt established S. aureus and S. epidermis biofilm. These data are also supported by clinical studies demonstrating that patients with prior treatment of statins have 
reduced disease progression and/or mortality associated with sepsis, pneumonia, acute infections, and bacteremia (26). However, it is unknown which statins are most effective against which species of pathogens.

Collectively, these studies indicate the potential of statins to be used as alternative antibiotics in clinical and military scenarios where chronic infections are plagued by biofilm formation and MDROs.

The objective of this study was to evaluate the antimicrobial and antibiofilm activity of a panel of commercially available statins against clinical strains of pathogens associated with chronic wounds. To achieve this goal, we screened the antimicrobial effects and biofilm inhibition of statins against various pathogens associated with wound infections. Based on the results of the preliminary screen, we then narrowed down top statin candidates for in-depth analysis against MDROs, established biofilm, persister cells, and cytotoxicity. We hypothesized that statins will outperform conventional antibiotics in the context of in vitro testing for applications in infected wound therapeutics, hence providing the foundation for preclinical testing.

\section{RESULTS}

\section{Identification of statins that are effective against wound-related pathogens and inhibit biofilm}

formation. The minimum inhibitory concentration (MIC) of 9 statins (simvastatin, pravastatin, atorvastatin, mevastatin, cerivastatin, pitavistatin, lovastatin, fluvastatin, and rosuvastatin) was determined against a panel of 6 wound-related pathogens (S. aureus, P. aeruginosa, coagulase-negative staphylococcus (CoNS), E. coli, Klebsiella spp., and $A$. baumannii) from concentrations 0 to $256 \mu \mathrm{g} / \mathrm{mL}$ (Table 1 ). All statins were ineffective against $P$. aeruginosa, E. coli, and Klebsiella spp. with MICs exceeding the maximum concentration tested, $256 \mu \mathrm{g} / \mathrm{mL}$. The only exception to this was simavastatin's MIC of $32 \mu \mathrm{g} / \mathrm{mL}$ for $P$. aeruginosa. Four out of the nine statins (44\%; pravastatin, mevastatin, lovastatin, and rosuvastatin) were ineffective against CoNS with MICs exceeding $256 \mu \mathrm{g} / \mathrm{mL}$. Atorvastatin, cerivastatin, pravastatin, and fluvastatin, had MICs of 256 against CoNS, while simvastatin was determined to have the lowest MIC against CoNS at $32 \mu \mathrm{g} / \mathrm{mL}$. Statins were most effective against $A$. baumannii, with each statin tested registering a MIC below the maximum concentration tested. Simvastatin had the lowest MIC of $32 \mu \mathrm{g} / \mathrm{mL}$, while the 8 other statins had a MIC of either 64 or $128 \mu \mathrm{g} / \mathrm{mL}$. Only three out of the nine (33\%) tested statins (simvastatin, atorvastatin, and fluvastatin, had a MIC below $256 \mu \mathrm{g} / \mathrm{mL}$ for $S$. aureus. Amongst these simvastatin had the lowest MIC at $32 \mu \mathrm{g} / \mathrm{mL}$. 
A secondary screen was then performed to determine the minimum biofilm inhibition concentration

(MBIC) of each statin against 3 pathogens, S. aureus, CoNS, and A. baumannii (Table 2) at an identical concentration range from 0 to $256 \mu \mathrm{g} / \mathrm{mL}$. P. aeruginosa, E. coli, and Klebsiella spp. were not investigated due to a lack of effect of statins against these species as determined in the first screen. Statins were largely ineffective against inhibition of $A$. baumannii biofilm with 3 statin's MBIC, pravastatin, lovastatin, and rosuvastatin, exceeding a concentration of $256 \mu \mathrm{g} / \mathrm{mL}$, while the 6 other statin's MBIC was $256 \mu \mathrm{g} / \mathrm{mL}$. Four out of the nine statins tested (44\%), simvastatin, pravastatin, cerivastatin, and lovastatin, had a MBIC below $256 \mu \mathrm{g} / \mathrm{mL}$ for CoNS, with simvastatin having the lowest MBIC of $8 \mu \mathrm{g} / \mathrm{mL}$. Of the three pathogens tested, statins were most effective at inhibiting the biofilm formation of $S$. aureus. Seven out of the nine statins tested (78\%) had a MBIC that was below $256 \mu \mathrm{g} / \mathrm{mL}$. Simvastatin, fluvastatin, and rosuvastatin had MBIC's of 8 $\mu \mathrm{g} / \mathrm{mL}$, while mevastatin was evaluated to have the lowest MBIC of $4 \mu \mathrm{g} / \mathrm{mL}$.

The results of these two screening panels indicated simvastatin as the lead drug candidate from the 9 statins tested. This was based on its relative broad spectrum activity against the 6 pathogens tested as determined by its MIC. Specifically, simvastatin was the only statin that showed efficacy against 4 out of the 6 pathogens tested ( $S$. aureus, $P$. aeruginosa, CoNS, and A. baumannii). Furthermore, simvastatin had a MBIC of $8 \mu \mathrm{g} / \mathrm{mL}$ for both $S$. aureus and CoNS. Moving forward, it was determined to perform a thorough characterization of simvastatin with respect to $S$. aureus, to determine its clinical potential regarding $S$. aureus related infections.

\section{MIC of simvastatin against MSSA and MRSA strains in comparison to other statins and conventional}

antibiotics. To initially evaluate the antimicrobial activity of simvastatin, MIC assays were performed on two different strains of $S$. aureus including the methicillin-susceptible $S$. aureus (MSSA) strain UAMS-1 and the MRSA strain USA300. MIC results were compared to conventional antibiotics used for S. aureus-related infections (tobramycin, gentamicin, vancomycin, and rifampin), as well as other statins, fluvastatin, mevastatin, and rosuvastatin for comparative purposes (Table 3). Simvastatin had a MIC of $32 \mu \mathrm{g} / \mathrm{mL}$ for both UAMS-1 and USA300. This finding is consistent with the previous data demonstrating that simvastatin has the lowest MIC 
when compared to other statins, regardless of strain of $S$. aureus, even in the comparison of MSSA to MRSA strains (Table 1). However, when compared to conventional antibiotics tobramycin, gentamicin, vancomycin and rifampin, simvastatin's MIC was $64 \times, 64 \times, 32 \times$, and 8,000× greater for each antibiotic respectively, regardless of MSSA or MRSA.

Determining whether simvastatin is bacteriostatic or bactericidal against UAMS-1. Simvastatin's mode of action was evaluated to be either bacteriostatic or bactericidal at 1, 2, 4, and $8 \times$ the MIC. This was determined by performing a modified minimum bactericidal concentration (MBC) assay. First a traditional MIC assay of simvastatin against a MSSA strain of $S$. aureus, UAMS-1 was performed. After the overnight incubation period, concentrations ranging from $1 / 2 \times$ to $8 \times$ the MIC of simvastatin were replated on agar plates and incubated overnight. The following day, bacterial growth was observed on all plates indicating that simvastatin's mechanism of action was bacteriostatic up to $8 \times$ the MIC (Table 4).

\section{Investigation of drug interaction between simvastatin and conventional antibiotics for S. aureus}

infections. To investigate the drug interaction between simvastatin and antibiotics (tobramycin, gentamicin, vancomycin, and rifampin), fractional inhibition concentration (FIC) testing was performed to evaluate if drug pairings enabled synergistic, antagonistic, or equivalent antimicrobial effects on UAMS-1. Testing revealed that simvastatin pairing with vancomycin, and rifampin resulted in no interaction for both UAMS-1 and USA300 with FIC indices ranging between 1 and 4 (Table 5). However an additive effect was observed for gentamicin with UAMS-1 and USA300 (FIC = 0.57). Tobramycin interestingly had an additive effect $(F I C=0.84)$ for UAMS-1, but was indifferent for USA300 (FIC $=1.208)$.

\section{Antimicrobial potency of statins against established S. aureus biofilm. The ability of simvastatin to} eradicate established $S$. aureus biofilm was assessed by performing a minimum biofilm eradication concentration (MBEC) assay. Fluvastatin and mevastatin were also included in this experiment due to their ability to inhibit biofilm at relatively low concentrations $\left(\mathrm{MBIC}_{\text {fluvastatin }}=8 \mu \mathrm{g} / \mathrm{mL}, \mathrm{MBIC}_{\text {mevastatin }}=4 \mu \mathrm{g} / \mathrm{mL}, \mathrm{Table} 2\right)$. 
Rifampin was used as a positive control due to its known potency against $S$. aureus biofilm (33). UAMS-1

biofilms were grown for $24 \mathrm{~h}$ with TSB supplemented with $10 \%$ plasma on polystyrene pegs. Afterwards, they were spiked with each of the indicated antimicrobials with concentrations ranging from 0 to $512 \mu \mathrm{g} / \mathrm{mL}$ and incubated for an additional $24 \mathrm{~h}$. Pegs were then sonicated in a recovery plate, serially diluted, and then plated, and the resulting CFU were enumerated. At each concentration, rifampin had a significant log reduction relative to mock-treated growth controls (Fig. 1). Log-reductions ranged from 1.6 to 4.8 in a dose dependent manner. All statins demonstrated minimal potency against established biofilm with a $<0.75$ log-reduction for each concentration relative to mock-treated biofilm. Additionally, all statins demonstrated a MBEC that exceeded $512 \mu \mathrm{g} / \mathrm{mL}$, while rifampin had a MBEC of $8 \mu \mathrm{g} / \mathrm{mL}$ (Table 6).

Investigating the effects of simvastatin on S. aureus persister cells and stationary phase cells. To further investigate simvastatin's efficacy against $S$. aureus related chronic infections, the ability to kill persister cells and stationary cells was evaluated. Persisters are phenotypic variants of normal cells with minimal metabolic activity that are a major factor for the drug tolerance of biofilms (34). Persister cells are a subpopulation found within the biofilm that survive antibiotic regimens due to their various dormant pathways. Removing the variable of drug diffusion through the ECM of the biofilm, a persister cell killing assay was performed to directly evaluate simvastin's ability to kill persisters. To start, gentamicin was added to an exponentially growing culture of UAMS-1 $\left(\sim 2.5 \times 10^{8} \mathrm{CFU} / \mathrm{mL}\right)$ at $10 \times \mathrm{MIC}$. This produces a standard biphasic killing pattern with surviving persister cells after $6 \mathrm{~h}$ with a surviving population of approximately $4 \times 10^{4}$ $\mathrm{CFU} / \mathrm{mL}$ (Fig. 2a). At $6 \mathrm{~h}$, a second antimicrobial was added to the culture at 10× MIC to evaluate the ability to eradicate the surviving persister cells. The added antimicrobials used in this experiment were rifampin, simvastatin, and CD437. CD437 is a retinoid antibiotic proven to be effective against persisters (35). The addition of rifampin and simvastatin did not kill the remaining persisters after $48 \mathrm{~h}$ of culture with $9.5 \times 10^{1}$ and $8.7 \times 10^{2} \mathrm{CFU} / \mathrm{mL}$ surviving cells respectively. However, the addition of CD437 eradicated the persisters by 24 h. 
In addition to investigating the ability of simvastatin to eradicate persisters, we examined the ability of

this statin to kill stationary cells of UAMS-1. The reason for this is because stationary phase $S$. aureus cells behave similarly to persister cells due to their dormancy and are very challenging to kill with standard antibiotics, as well as a range of other various antimicrobials (35-37). Therefore, stationary phase cells provide an alternative model to challenge the efficacy of an antimicrobial to kill drug-tolerant phenotypes. To start, a population of nongrowing UAMS-1 at $\sim 10^{10} \times \mathrm{CFU} / \mathrm{mL}$ were spiked with $10 \times$ the MIC of gentamicin, rifampin, vancomycin, daptomycin, and simvastatin (Fig. 2b). Viable cells were sampled and counted for every $24 \mathrm{~h}$ for up to 4 days. All antimicrobials tested had minimal activity against the stationary phase cells and no significant differences were observed relative to the growth control.

Cytotoxic effects of Simvastatin on mammalian cells. To determine the adverse effects of simvastatin on mammalian cells, the cytotoxicity was measured using an XTT proliferation assay. Viability of human osteoblasts were treated with either vancomycin, rifampin, or simvastatin at concentrations ranging from 0 to $512 \mu \mathrm{g} / \mathrm{mL}$. The antibiotics, vancomycin and rifampin, demonstrated favorable cell viability with all concentrations tested exceeding $61 \%$ cell viability except for $512 \mu \mathrm{g} / \mathrm{mL}$ of rifampin which had $60 \%$ cell viability (Fig. 3a-b, d). However, simvastatin had a limited viability profile with severe cytotoxicity with concentrations above the MIC of $32 \mu \mathrm{g} / \mathrm{mL}$ (Fig. 3c, d).

\section{DISCUSSION}

The association of MDROs with wound infection is a critical problem for both military and civilian medical practices. The ability of pathogens to self-produce biofilm protected communities coupled with the increasingly rising rate of antibiotic resistance greatly enhances the recalcitrance and persistence of wound infections. Therefore it is crucial to identify antibiotic alternatives that are effective against MDRO-associated infections. One possible avenue is the repurposing the cholesterol-lowering statin family of drugs as novel antimicrobials (26). Previous studies have shown the antibacterial activity of statins, but conflicting reported results for various species have prompted the need for a comprehensive screen encompassing various pathogens, as well as 
their efficacy against dormant phenotypes such as biofilm and associated persister cells $(27-29,38)$. In this study, we evaluated the antimicrobial activity of nine statins against clinical pathogens associated with wound infections.

The antibacterial effects of statins was first reported in 2001 when Liappis et al. performed a restrospective study finding that mortality attributed to $S$. aureus bacteremia was reduced for patients taking statins (39). This initial finding led to a breakthrough of subsequent retrospective studies and meta-analyses that found similar results finding that the prior use of statins reduced the disease progression and/or mortality of pneumonia and sepsis in clinical cases (40-44). However, select retrospective and meta-analyses have reported confounding results and the limited amount of prospective randomized trials have also supported the finding of no improvement in clinical outcomes (45-49). Furthermore, trials investigating the de novo treatment of infections with statins have shown no favorable results (50). Yet all of these studies did not account for or adjust the type of statin with the pathogen causing the infection. Therefore, these clinical studies have prompted the need for in vitro characterization of statins to identify potency with specific pathogens and strains. Various studies have been published reporting the antimicrobial effects of statins by determining the MIC on a wide spectrum of pathogens responsible for causing infections. Hennessy et al. published a comprehensive review encompassing the findings of all these studies (26). A major discrepancy amongst these studies is the large range of MICs reported ranging from 15 to $500 \mu \mathrm{g} / \mathrm{mL}$. Additionally, limited studies have examined the relationship between antimicrobial concentrations of statins with viability of mammalian cell lines and also efficacy against biofilm and associated persister cells. Therefore, we determined the need to investigate a systematic approach to screen a panel of pathogens with all nine available statins, seven of which are FDA-approved, to determine the relationship between statin-pathogen efficacies. Additionally, effects on biofilm, persister cells, and mammalian cell cytotoxicity were also interrogated.

Studies that examined similar pathogens generally reported similar MICs to the ones reported here within $(27-32,51)$. With regards to MBICs, statins were most active against the clinical isolates of $S$. aureus and $A$. baumannii with MBICs being reported the lowest for gram-positive $S$. aureus. This is consistent with Wang et al who also found the ability of statins to inhibit $S$. aureus biofilm formation, as well as Hennessy et al. who determined the ability of simvastatin to inhibit the formation of $P$. aeruginosa biofilm $(30,51)$. Interestingly 
in this study, statin MBICs against $S$. aureus were lower to the $\mathrm{MIC}$ counterpart $(\mathrm{MIC}=32 \mu \mathrm{g} / \mathrm{mL}, \mathrm{MBIC}=8$ $\mu \mathrm{g} / \mathrm{mL}$ ), however $A$. baumannii had generally higher MBICs $(\mathrm{MIC}=32 \mu \mathrm{g} / \mathrm{mL}, \mathrm{MBIC}=256 \mu \mathrm{g} / \mathrm{mL})$. One possibility contributing to the difference in $\mathrm{MBIC}$ is the known ability of the statins to inhibit the expression of microbial surface components recognizing adhesive matrix molecules (MSCRAMMs) expression in the quorum sensing pathway which has been shown to play a pivotal role in Staphylococcal biofilm formation (52). Furthermore, since this trend was only observed with $S$. aureus, it could be suggested that the statins were only able to inhibit the MSCRAMMs of $S$. aureus and not $A$. baumannii.

After the initial MIC and MBIC screening, it was determined that simvastatin was the top statin candidate due to its broad antimicrobial potency for all test pathogens, but more importantly its efficacy specifically against $S$. aureus (MIC $=32 \mu \mathrm{g} / \mathrm{mL}, \mathrm{MBIC}=8 \mu \mathrm{g} / \mathrm{mL}$ ). Interestingly it has been identified by other groups that simvastatin appears to be the statin with the highest antimicrobial potential. For example, Thangamani et al performed a similar planktonic bacteria screening paradigm against $S$. aureus and $P$. aeruginosa and identified simvastatin as the lead drug candidate (31). Despite its potential, our study showed that further characterization of simvastatin against $S$. aureus revealed no potency against established $S$. aureus biofilm. This is not consistent with previous data that suggests that simvastatin is effective against established $S$. aureus biofilm $(31,32)$. However this can be explained by the methods used to interrogate efficacy against established biofilm. Graziano et al. and Thang et al. both utilized crystal violet (CV)-based biofilm assays, which enables the visualization of biofilm thickness and quantification of biomass after alcohol solubilization. However, this methodology is not accurate for calculating cell viability of the biofilm, which is the fundamental result to understand if recurrence of infection will occur in a biofilm-based infection, not biomass (53). Overall, the lack of potency for simvastatin against not only established biofilm, but also persister cells indicates the poor potential for treatment of chronic $S$. aureus-related infection which are defined by this bacterial phenotypes (54).

An alarming barrier to the antimicrobial repurposing of statins is the low plasma concentrations recorded for patients. Peak plasma concentrations range from 0.01 to $0.3 \mu \mathrm{g} / \mathrm{mL}$ for patients with high cholesterol prescribed oral statins $(55,56)$. Meanwhile, the lowest reported $S$. aureus MIC in this study for any statin is $8 \mu \mathrm{g} / \mathrm{mL}$, which is 27 to 800 times the reported plasma levels. To achieve concentrations equivalent to 
the MIC of statins and circumvent systemic toxicity issues, local delivery directly to infection site is a proposed alternative. A clinical example of this is in the scenario of implant-associated osteomyelitis, where antibioticladen calcium cement spacers are utilized to deliver high concentrations of antibiotics to the infection site (57). These spacers enable both the management of infection, while simultaneously supporting bone formation. The addition of statins, specifically simvastatin, to these spacers can possibly enhance desired outcomes. Simvastatin does not only possess antimicrobial properties that can aid in the management of orthopedic infections, but it also has been shown to enhance BMP-2 expression in osteoblasts and bone healing at relatively low concentrations $(58,59)$. Additionally, Yoshii et al. demonstrated that polyurethane scaffolds incorporated with lovastatin enhanced bone regeneration in a critical-sized defect in rat femurs (60). These findings suggest that statins can aid in the two needed outcomes for osteomyelitis, infection management and bone growth. Yet, a major limitation is the small therapeutic window which statins produce. In the context of osteomyelitis, simvastatin's MIC is $32 \mathrm{ug} / \mathrm{mL}$, but it is also cytotoxic against bone forming osteoblasts at concentrations greater than $32 \mathrm{ug} / \mathrm{mL}$. Osteoblast's viability is critical for the success of treating osteomyelitis patients due to its essential role in bone formation. Therefore, in the context of statin local delivery to treat implant-associated osteomyelitis, the application of simvastatin is very limited based on its limited therapeutic window and additionally its lack of synergy with conventional antibiotics. It is also presumed that a similar cytotoxic effect of statins in any local delivery application would be a major limiting factor.

The limited therapeutic window is a major concern for the implementation of statins in both systemic and local delivery. The evidence demonstrated here showcased that statins have antimicrobial concentrations that greatly exceed the reported clinical ranges and also are ineffective against established biofilm. Furthermore, the effective MIC of simvastatin for MSSA and MRSA fall just within the maximum threshold for osteoblast cell viability. Unfortunately this result cannot be explained by the direct antibacterial mechanism of action for statins against $S$. aureus and other pathogens, for it is unknown. But the bacteriostatic effect is thought to be attributed to the binding and inhibition of the active site of 3-hydroxy-3-methylgutaryl-coenzyme A (HMF-CoA) reducatase (HMGR), which is the mechanism responsible for the cholesterol-lowering effect (61, 62). However, statins have been shown to be effective against pathogens with and without the presence of HMGR $(28,29)$. An alternative theory is that clinical outcomes observed in patients prescribed with statins are 
attributed to statin's multi-faceted effects instead of direct antibacterial effects. The most notable effect that supports this theory is the ability of statins to modulate the host inflammatory response. For example, mice treated with simvastatin in a sepsis model had reduced secretion of proinflammtory chemokines that also resulted in reduced lung injury (63). Similar findings have also been observed in studies demonstrating the ability of cerivastatin to attenuate inflammatory responses $(64,65)$. With these findings in mind, it is best to focus research efforts on statin's downstream effects on various inflammatory processes instead of direct antibacterial effects. For this avenue would best explain the observed prophylactic effects of statins in clinical scenarios and help maximize the research geared towards optimizing therapeutic potential. Lastly, it is important to note the limitations of in vitro studies and the differences observed comparing in vivo to in vitro studies. With that in mind, in vivo studies are warranted to investigate the toxic side-effects of statins at antimicrobial concentrations.

\section{CONCLUSION}

This study executed a screening methodology investigating the MIC and MBIC of statins against various bacterial clinical isolates associated with wound infections. Simvastatin was identified as a lead-drug candidate with the highest potential due to its broad antimicrobial potency against $S$. aureus, $P$. aeruginosa, CoNS, and A. naumannii, as well as its ability to inhibit $S$. aureus and CoNS biofilm. Due to its relatively low S. aureus MIC and MBIC, further in vitro characterization was performed investigating its effects against MSSA and MRSA strains, established biofilm, persisters cells, and mammalian cell cytotoxicity to further uncover its potential. However, characterization displayed limited antimicrobial capacity due to its relatively high MICs for MSSA and MRSA in comparison to conventional antibiotics, inefficiency against established biofilm, and cytotoxic effects against osteoblasts. Together this creates a minimal therapeutic window. Future studies should investigate the pleiotropic effects of statins to indirectly attenuate the disease progression of infection which would best explain the reported prophylactic effects in clinic instead of investigating direct antimicrobial effects.

\section{METHODS}

\section{Study Design}


Two separate screens were performed to identify statins that were effective against species of bacteria in planktonic and the ability to inhibit biofilm formation. The first screen performed a standard MIC screen to investigate the efficacy of nine of different statins against six different wound-related pathogens, $S$. aureus, $P$. aeruginosa, CoNS, E. coli, Klebsiella spp., and A. baumannii. Afterwards, a secondary screen was performed to investigate the minimal biofilm inhibitory concentration (MBIC) of three different biofilm forming species, $S$, aureus, CoNS, and $A$. baumannii. The results of these two screens were then analyzed to identify a lead candidate that was most effective in the two screens against bacterial species. A lead candidate was then thoroughly characterized against specific strains of bacteria to reveal potential in clinical applications. This characterization consisted of a MIC panel against a drug resistant strain, determination of the mode of action (i.e. bacteriostatic vs bactericidal), synergy with conventional antibiotics, efficacy against established biofilm, ability to kill persister cells, and lastly cytotoxicity against a mammalian cell line.

\section{Bacterial strains and growth conditions}

All clinical bacterial isolates used for the initial MIC and MBIC screening ( $S$. aureus, $P$. aeruginosa, coagulase CoNS, E. coli, Klebsiella spp., A. baumannii) were obtained from a strain repository at the San Antonio Military Medical Center at Fort Sam Houston, TX USA, which were collected from patients as a part of care and not related to research. In subsequent experiments $S$. aureus, UAMS-1 and USA300 were used. UAMS-1 is a MSSA clinical isolate and USA300 is a community-associated (MRSA). All S. aureus strains used in this study are known biofilm forming strains (66). Overnight cultures of all bacterial isolates were grown for $16-18 \mathrm{~h}$ in tryptic soy broth (TSB) or cation-adjusted Mueller Hinton broth (MHB) at $37^{\circ} \mathrm{C}$ on an orbital shaker with aeration at 225 rotation per minute (RPM). Further detail on growth conditions specific to each experiment are described in the following respective sections.

\section{Drug Stocks}

Statins were obtained from Sigma Aldrich (St. Louis, MO) or Selleckchem (Houston, TX). Antibiotics were also purchased from Sigma Aldrich or Selleckchem. Additionally, CD437 was obtained from R\&D Systems. All 
antimicrobials were solubilized and prepared per the manufacturer's recommendation and frozen and stored at $-80^{\circ} \mathrm{C}$ until use.

\section{Minimum Inhibitory Concentration Assay}

The MIC was determined by the broth microdilution method in accordance to standards set by the Clinical and Laboratory Standards Institute (CLSI) (67). Briefly, individual wells of a 96-well plate contained 2-foldincreasing concentrations ( 0 to $256 \mu \mathrm{g} / \mathrm{mL}$ ) of antimicrobials in MHB. Overnight cultures of clinical isolates (1618 h; S. aureus, P. aeruginosa, CoNS, E. coli, Klebsiella spp., A. baumannii) were diluted and then used to inoculate each well achieving a final concentration of $5 \times 10^{5} \mathrm{CFU} / \mathrm{mL}$. Following overnight static incubation at $37^{\circ} \mathrm{C}$, the lowest concentration of antimicrobial lacking visible bacterial growth was defined as the MIC. All MIC assays were performed in duplicate to confirm results.

\section{Minimum Biofilm Inhibitory Concentration}

Bacteria (S. aureus, CoNS, A. baumannii) were grown from overnight cultures (16-18 h) in MHB and adjusted to a concentration of $\sim 10^{8} \mathrm{CFU} / \mathrm{mL}$. Bacteria were then diluted 1:100 in MHB and inoculated into individual wells of a 96 well MBEC plate (Innovotech, Edmonton, CA) containing increasing concentrations ( 0 to 256 $\mu \mathrm{g} / \mathrm{mL}$ ) of statins, to achieve a final volume of $200 \mu \mathrm{L}$. Overnight incubation at $37^{\circ} \mathrm{C}$ enabled biofilm formation on the polystyrene pegs of the MBEC lid for each well. After the overnight incubation, media was removed, pegs were gently washed with $2 \times$ phosphate buffered saline (PBS), and then stained with $0.1 \%$ CV at room temperature. Plates were then washed and biomass was quantified by measuring the $\mathrm{OD}_{570 \mathrm{~nm}}$ following solubilization of attached statins in $70 \% \mathrm{EtOH}$. MBIC was reported as reduction of $\geq 50 \%$ of the solubilized CV for the control untreated groups.

\section{Mode of Action: Bactericidal vs. Bacteriostatic}

To determine the mode of action of antimicrobials as bactericidal or bacteriostatic, a modified MBC assay was performed. First, a procedure identical to the previously described MIC assay was performed. Following overnight incubation (16-18 h), wells that contained concentrations of antimicrobials that exhibited no growth of 
S. aureus UAMS-1 were enumerated and spot plated on blood agar (tryptic soy agar with $5 \%$ sheep blood). In addition to these concentrations, the highest concentration of antimicrobial that showed growth was also plated as a growth control. The next day following overnight incubation the blood agar plates were assessed for bacterial growth. If visible CFUs were observed then the mode of action was defined as bacteriostatic for the corresponding concentration. If no bacterial growth was observed after incubation, then the mode of action was defined as bactericidal. This experiment was performed in duplicate to confirm results.

\section{Fractional Inhibitory Concentration Assay}

Drug interactions between simvastatin and antibiotics were determined by performing a checkerboard test and calculating the FIC index, as established in literature (68). Individual wells of a 96-well microtiter plate were inoculated with $\sim 1 \times 10^{5} \mathrm{CFU} / \mathrm{mL}$ of $S$. aureus UAMS-1 in MHB. Each row and column of the plate contained 2 -fold increasing increment concentrations of $\operatorname{simvastatin}(0 \times, 0.031 \times, 0.063 \times, 0.125 \times, 0.25 \times, 0.5 \times, 1 \times$, and $2 \times$ the $\mathrm{MIC})$ and either tobramycin, gentamicin, vancomycin or rifampin $(0 \times, 0.031 \times, 0.063 \times, 0.125 \times, 0.25 \times, 0.5 \times$, $1 \times, 2 \times$, and $4 \times$ the MIC). Plates with each possible combination of drug pairings with simvastatin were incubated for $16-18 \mathrm{~h}$ at $37^{\circ} \mathrm{C}$. Growth was identified by the unaided eye. The FIC was determined using the following formula:

$$
\frac{A}{M I C_{A}}+\frac{B}{M I C_{B}}=\text { FIC Index }
$$

where $\mathrm{MIC}_{\mathrm{A}}$ and $\mathrm{MIC}_{\mathrm{B}}$ are the MICs of the drugs being examined when acting alone and $\mathrm{A}$ and $\mathrm{B}$ are the $\mathrm{MIC}$ of the corresponding drug in combination. The average of the FIC indexes was taken and used to determine the overall interaction of the drugs. Synergy was defined as an FIC index less than or equal to 0.5 , antagonism was defined as a FIC index greater than 4, and indifference was defined as an FIC index greater than 0.5 and less than 4. These experiments were conducted in duplicate.

\section{Persister Cell Antimicrobial Susceptibility Assay}

An overnight culture of $S$. aureus UAMS- 1 was diluted in $5 \mathrm{~mL}$ of $\mathrm{MHB}$ to $1 \times 10^{8} \mathrm{CFU} / \mathrm{mL}$ and then treated with gentamicin at $10 \times$ the MIC. Treated cultures were then incubated $37^{\circ} \mathrm{C}$ with aeration at $225 \mathrm{rpm}$. At designated time points $(0,2,4$, and $6 \mathrm{~h}), 100 \mu \mathrm{L}$ samples were removed and centrifuged for two minutes at 
$13.3 \times g$. The resulting supernatant was removed and the cell pellet was resuspended in PBS. Serial dilutions were then preformed and $10 \mu \mathrm{L}$ of each dilution was plated in triplicate on blood agar plates for CFU analysis. Plates were statically incubated overnight at $37^{\circ} \mathrm{C}$. At the $6 \mathrm{~h}$ time point, the surviving bacteria population of each culture consists of persister cells that survive the initial gentamicin treatment. At this point, an additional antimicrobial, either rifampin, simvastatin, or CD437, was added to target and eliminate the surviving persister cell population. Samples were taken and counted for CFUs at 24 and $48 \mathrm{~h}$. This experiment was conducted in duplicate.

In addition to the persister killing assay, a stationary-phase killing assay was performed. Stationaryphase cells of $S$. aureus have been used in literature to model persister cells and test antimicrobial susceptibility $(35,37)$. To execute this experiment, stationary phase populations of $\mathrm{S}$. aureus UAMS-1 were prepared by preparing an overnight culture and incubation at $37^{\circ} \mathrm{C}$ with aeration at $225 \mathrm{rpm}$ for $16-18 \mathrm{~h}$. The following day, the stationary phase cultures were subdivided into individual culture tubes, tested for CFUs (time $=0 \mathrm{~h}$ ) and spiked with $10 \times$ the MIC of conventional antibiotics, rifampin, vancomycin, daptomycin, and simvastatin. Viable cell numbers were calculated each day, for up to 4 days, by removing $100 \mu \mathrm{L}$ from each culture, centrifuging at $10,000 \mathrm{~g}$ for $3 \mathrm{~min}$, then resuspended in PBS. Samples were then enumerated by spot plating serial dilution on blood agar plates. This experiment was repeated in duplicate.

\section{Minimum Biofilm Eradication Concentration Assay}

Established S. aureus UAMS-1 biofilms were tested for susceptibility against simvastatin, mevastatin, fluvastatin, and rifampin. Biofilm survival assays were performed in 96 well MBEC plates with a polystyrene pegged lid. Briefly, cultures of UAMS-1 were allowed to grow overnight and then adjusted to $5.5 \times 10^{5} \mathrm{CFU} / \mathrm{mL}$ in TSB supplemented with $10 \%$ human plasma. Each well was inoculated with $200 \mu \mathrm{L}$ of bacteria suspension and allowed to incubate for $24 \mathrm{~h}$ at $37^{\circ} \mathrm{C}$ at $110 \mathrm{rpm}$. After incubation, the peg lid containing the biofilms was gently washed with PBS and was placed onto a challenge plate with fresh medium containing 2-fold serial dilutions of selected drugs in each well. The challenged biofilm was incubated for 24 hours under the same conditions. Biofilm pegs were then washed and sonicated at $50 / 60 \mathrm{~Hz}$ in a recovery plate containing $200 \mu \mathrm{L}$ of TSB for 30 minutes. $100 \mu \mathrm{L}$ of the recovery media was set aside and incubated overnight to determine the 
MBEC. The remaining volume was assessed for viability of biofilm-associated cells by performing serial dilutions of each well and spotted on MHB agar for comparison of log reductions relative to a growth control mock treated with dimethyl sulfoxide (DMSO). The MBEC was defined as the concentration of antimicrobial that produced no visible bacterial growth in the recovery media after overnight incubation for all samples.

431

432

433

434

435

436

437

438

439

440

441

442

443

444

445

446

447

448

449

450

451

452

453

\section{Cytotoxicity Assay}

The cytotoxic effects of antimrobials on human osteoblasts were identified using the XTT (2,3-bis-(2-methoxy4-nitro-5-sulfophenyl)-5-[(phenylamino) carbonyl]-2Htetrazolium hydroxide) cell proliferation assay. Human osteoblasts (Lonza Biologics, Portsmouth, $\mathrm{NH}$ ) were grown to confluency in phenol red free osteoblast basal medium (OBM; PromoCell, Heidelberg, DE) were seeded at a concentration of $1 \times 10^{5} \mathrm{CFU} / \mathrm{mL}$ into each well and allowed to attach overnight. Antimicrobials of interest were diluted in OBM without phenol red and used to treat the attached cells. The plate was statically incubated for $24 \mathrm{~h}$ at $37^{\circ} \mathrm{C}$. The following day the cells were washed three times with fresh $1 \times$ PBS and then new media was added. $50 \mu \mathrm{L}$ of XTT/PMS was next added to each well. After another incubation period of three hours, solutions were transferred to a new well plate and the absorbance was measured at $495 \mathrm{~nm}$. Toxicity was characterized as percent cell viability relative to mocktreated growth control.

\section{LIST OF ABBREVIATIONS}

Coagulase-negative staphylococcus (CoNS), Center for Disease Control (CDC), colony forming units (CFU), Clinical and Laboratory Standards Institute (CLSI), crystal violet (CV), dimethyl sulfoxide (DMSO), extracellular matrix (ECM), Food and Drug Administration (FDA), fractional inhibition concentration (FIC), 3-hydroxy-3methylgutaryl-coenzyme A (HMF-CoA), 3-hydroxy-3-methylgutaryl-coenzyme A reducatase (HMGR), minimum bactericidal concentration (MBC), minimum biofilm eradication concentration (MBEC), minimum biofilm inhibition concentration (MBIC), multidrug-resistance-organisms (MDROs), Mueller Hinton broth (MHB), minimum inhibitory concentrations (MIC), methicillin-resistant S. aureus (MRSA), microbial surface components recognizing adhesive matrix molecules (MSCRAMMs), N-methyl dibenzopyrazine methyl sulfate (PMS), rotation per minute (RPM), tryptic soy broth (TSB), vancomycin-resistant enterococci (VRE), 
454 vancomycin-resistant S. aureus (VRSA), (2,3-bis-(2-methoxy-4-nitro-5-sulfophenyl)-5-[(phenylamino)

455 carbonyl]-2Htetrazolium hydroxide) (XTT).

456

\section{DECLARATIONS}

458 The views expressed in this article (book, speech, etc.) are those of the author(s) and do not reflect the official 459 policy or position of the U.S. Army Medical Department, Department of the Army, Department of Defense, or 460 the U.S. Government.

\section{Ethics and approval to participate}

Not Applicable

\section{Consent for publication}

Not Applicable

\section{Availability of data and materials}

The datasets analyzed during the current study are available from the corresponding author on reasonable request.

\section{Competing Interests}

The authors declare that they have no competing interests.

\section{Funding}

This work was funded by the U.S. Army Medical Research and Materiel Command. Additionally, RPT was supported by a fellowship to the Postgraduate Research Participation Program at the U.S. Army Institute of Surgical Research (USAISR) administered by the Oak Ridge Institute for Science and Education through an interagency agreement between the U.S. Department of Energy and the USAISR. 
Author's contributions

$\mathrm{RPT}$ and $\mathrm{KL}$ were involved in the data collection, statistical analysis, and interpretation of all the $S$. aureus

MIC, MBEC, persister cell, and cytotoxicity data. RL and DR assisted in the data collection of the MBEC assays. CJS and AA performed, collected, analyzed, and interpreted the data concerning the statin screen against wound related pathogens (MIC and MBIC). RPT was the major contributor in writing the manuscript, with sections added by KL. JCW was responsible for the project coordination and manuscript revision. This study was originally conceived by CJS and JCW. All authors read, provided feedback, and approved the final manuscript.

\section{Acknowledgements}

The authors would like to thank Dr. Katrin Mende, Director of the Molecular Biology Laboratory at the San Antonio Military Medical Center, for contributing the clinical isolates used in this study.

\section{REFERENCES}

1. Tribble DR, Murray CK, Lloyd BA, Ganesan A, Mende K, Blyth DM, et al. After the Battlefield: Infectious Complications among Wounded Warriors in the Trauma Infectious Disease Outcomes Study. Military medicine. 2019;184(Supplement_2):18-25.

2. Harris AM, Althausen PL, Kellam J, Bosse MJ, Castillo R, Group aTLEAPS. Complications Following LimbThreatening Lower Extremity Trauma. Journal of orthopaedic trauma. 2009;23(1):1-6.

3. Akers KS, Mende K, Cheatle KA, Zera WC, Yu X, Beckius ML, et al. Biofilms and persistent wound infections in United States military trauma patients: a case-control analysis. BMC Infect Dis. 2014;14:190-.

4. Olsen I. Biofilm-specific antibiotic tolerance and resistance. European journal of clinical microbiology \& infectious diseases : official publication of the European Society of Clinical Microbiology. 2015;34(5):877-86.

5. Nussbaum SR, Carter MJ, Fife CE, DaVanzo J, Haught R, Nusgart M, et al. An Economic Evaluation of the Impact, Cost, and Medicare Policy Implications of Chronic Nonhealing Wounds. Value in health : the journal of the International Society for Pharmacoeconomics and Outcomes Research. 2018;21(1):27-32.

6. D'Avignon LC, Saffle JR, Chung KK, Cancio LC. Prevention and management of infections associated with burns in the combat casualty. The Journal of trauma. 2008;64(3 Suppl):S277-86.

7. Erol S, Altoparlak U, Akcay MN, Celebi F, Parlak M. Changes of microbial flora and wound colonization in burned patients. Burns : journal of the International Society for Burn Injuries. 2004;30(4):357-61.

8. Barret JP, Herndon DN. Effects of burn wound excision on bacterial colonization and invasion. Plastic and reconstructive surgery. 2003;111(2):744-50; discussion 51-2.

9. Shin EH, Sabino JM, Nanos GP, 3rd, Valerio IL. Ballistic trauma: lessons learned from iraq and afghanistan. Seminars in plastic surgery. 2015;29(1):10-9.

10. Bowyer G. Debridement of extremity war wounds. The Journal of the American Academy of Orthopaedic Surgeons. 2006;14(10 Spec No.):S52-6.

11. Anglen JO. Wound irrigation in musculoskeletal injury. The Journal of the American Academy of Orthopaedic Surgeons. 2001;9(4):219-26. 
12. Fang R, Dorlac WC, Flaherty SF, Tuman C, Cain SM, Popey TL, et al. Feasibility of negative pressure wound therapy during intercontinental aeromedical evacuation of combat casualties. The Journal of trauma. 2010;69 Suppl 1:S140-5.

13. Couch KS, Stojadinovic A. Negative-pressure wound therapy in the military: lessons learned. Plastic and reconstructive surgery. 2011;127 Suppl 1:117S-30S.

14. Gross M. Antibiotics in crisis. Current Biology. 2013;23(24):R1063-R5.

15. Proctor R. Respiration and Small Colony Variants of Staphylococcus aureus. Microbiol Spectr. 2019;7(3).

16. Garcia LG, Lemaire S, Kahl BC, Becker K, Proctor RA, Denis O, et al. Antibiotic activity against small-colony variants of Staphylococcus aureus: review of in vitro, animal and clinical data. The Journal of antimicrobial chemotherapy. 2013;68(7):1455-64.

17. Brady RA, Leid JG, Calhoun JH, Costerton JW, Shirtliff ME. Osteomyelitis and the role of biofilms in chronic infection. FEMS immunology and medical microbiology. 2008;52(1):13-22.

18. Oliveira PR, Carvalho VC, Lima ALM. Optimizing the treatment of osteomyelitis with antimicrobial drugs: current concepts. Current Orthopaedic Practice. 2017;28(2):208-12.

19. Masters EA, Trombetta RP, de Mesy Bentley KL, Boyce BF, Gill AL, Gill SR, et al. Evolving concepts in bone infection: redefining "biofilm", "acute vs. chronic osteomyelitis", "the immune proteome" and "local antibiotic therapy". Bone Research. 2019;7(1):20.

20. Olson ME, Ceri H, Morck DW, Buret AG, Read RR. Biofilm bacteria: formation and comparative susceptibility to antibiotics. Canadian Journal of Veterinary Research. 2002;66(2):86-92.

21. Nickel JC, Ruseska I, Wright JB, Costerton JW. Tobramycin resistance of Pseudomonas aeruginosa cells growing as a biofilm on urinary catheter material. Antimicrobial agents and chemotherapy. 1985;27(4):619-24.

22. Costerton JW, Lewandowski Z, Caldwell DE, Korber DR, Lappin-Scott HM. Microbial biofilms. Annual review of microbiology. 1995;49:711-45.

23. Otto M. Staphylococcal biofilms. Curr Top Microbiol Immunol. 2008;322:207-28.

24. Debnath A, Ndao M, Reed SL. Reprofiled drug targets ancient protozoans: drug discovery for parasitic diarrheal diseases. Gut microbes. 2013;4(1):66-71.

25. Dudley JT, Deshpande T, Butte AJ. Exploiting drug-disease relationships for computational drug repositioning. Briefings in Bioinformatics. 2011;12(4):303-11.

26. Hennessy E, Adams C, Reen FJ, O'Gara F. Is There Potential for Repurposing Statins as Novel Antimicrobials? Antimicrob Agents Chemother. 2016;60(9):5111-21.

27. Jerwood S, Cohen J. Unexpected antimicrobial effect of statins. The Journal of antimicrobial chemotherapy. 2008;61(2):362-4.

28. Masadeh M, Mhaidat N, Alzoubi K, Al-Azzam S, Alnasser Z. Antibacterial activity of statins: a comparative study of atorvastatin, simvastatin, and rosuvastatin. Ann Clin Microbiol Antimicrob. 2012;11:13-.

29. Welsh A-M, Kruger P, Faoagali J. Antimicrobial action of atorvastatin and rosuvastatin. Pathology - Journal of the RCPA. 2009;41(7):689-91.

30. Wang CC, Yang PW, Yang SF, Hsieh KP, Tseng SP, Lin YC. Topical simvastatin promotes healing of Staphylococcus aureus-contaminated cutaneous wounds. International wound journal. 2016;13(6):1150-7.

31. Thangamani S, Mohammad H, Abushahba MFN, Hamed MI, Sobreira TJP, Hedrick VE, et al. Exploring simvastatin, an antihyperlipidemic drug, as a potential topical antibacterial agent. Scientific Reports. 2015;5:16407.

32. Graziano TS, Cuzzullin MC, Franco GC, Schwartz-Filho HO, de Andrade ED, Groppo FC, et al. Statins and Antimicrobial Effects: Simvastatin as a Potential Drug against Staphylococcus aureus Biofilm. PLoS One. 2015;10(5):e0128098-e.

33. Sanchez CJ, Shiels SM, Tennent DJ, Hardy SK, Murray CK, Wenke JC. Rifamycin Derivatives Are Effective Against Staphylococcal Biofilms In Vitro and Elutable From PMMA. Clinical Orthopaedics and Related Research ${ }^{\circledR}$. 2015;473(9):2874-84.

34. Spoering AL, Lewis K. Biofilms and planktonic cells of Pseudomonas aeruginosa have similar resistance to killing by antimicrobials. J Bacteriol. 2001;183(23):6746-51.

35. Kim W, Zhu W, Hendricks GL, Van Tyne D, Steele AD, Keohane CE, et al. A new class of synthetic retinoid antibiotics effective against bacterial persisters. Nature. 2018;556(7699):103-7. 
36. Johnson PJT, Levin BR. Pharmacodynamics, Population Dynamics, and the Evolution of Persistence in Staphylococcus aureus. PLOS Genetics. 2013;9(1):e1003123.

37. Conlon BP, Nakayasu ES, Fleck LE, LaFleur MD, Isabella VM, Coleman K, et al. Activated ClpP kills persisters and eradicates a chronic biofilm infection. Nature. 2013;503(7476):365-70.

38. Bergman P, Linde C, Pütsep K, Pohanka A, Normark S, Henriques-Normark B, et al. Studies on the antibacterial effects of statins--in vitro and in vivo. PLoS One. 2011;6(8):e24394-e.

39. Liappis AP, Kan VL, Rochester CG, Simon GL. The effect of statins on mortality in patients with bacteremia. Clinical infectious diseases : an official publication of the Infectious Diseases Society of America. 2001;33(8):1352-7. 40. Dobesh PP, Olsen KM. Statins role in the prevention and treatment of sepsis. Pharmacological research. 2014;88:31-40.

41. Kouroumichakis I, Papanas N, Proikaki S, Zarogoulidis P, Maltezos E. Statins in prevention and treatment of severe sepsis and septic shock. European journal of internal medicine. 2011;22(2):125-33.

42. Schlienger RG, Fedson DS, Jick SS, Jick H, Meier CR. Statins and the risk of pneumonia: a population-based, nested case-control study. Pharmacotherapy. 2007;27(3):325-32.

43. Mortensen EM, Restrepo MI, Anzueto A, Pugh J. The effect of prior statin use on 30-day mortality for patients hospitalized with community-acquired pneumonia. Respir Res. 2005;6(1):82-.

44. Ou SY, Chu H, Chao PW, Ou SM, Lee YJ, Kuo SC, et al. Effect of the use of low and high potency statins and sepsis outcomes. Intensive care medicine. 2014;40(10):1509-17.

45. Chen M, Ji M, Si X. The effects of statin therapy on mortality in patients with sepsis: A meta-analysis of randomized trials. Medicine (Baltimore). 2018;97(31):e11578-e.

46. Majumdar SR, McAlister FA, Eurich DT, Padwal RS, Marrie TJ. Statins and outcomes in patients admitted to hospital with community acquired pneumonia: population based prospective cohort study. BMJ. 2006;333(7576):999-.

47. Thomas G, Hraiech S, Loundou A, Truwit J, Kruger P, McAuley DF, et al. Statin therapy in critically-ill patients with severe sepsis: a review and meta-analysis of randomized clinical trials. Minerva anestesiologica. 2015;81(8):921-30.

48. Singh RK, Agarwal V, Baronia AK, Kumar S, Poddar B, Azim A. The Effects of Atorvastatin on Inflammatory Responses and Mortality in Septic Shock: A Single-center, Randomized Controlled Trial. Indian J Crit Care Med. 2017;21(10):646-54.

49. Truwit JD, Bernard GR, Steingrub J, Matthay MA, Liu KD, Albertson TE, et al. Rosuvastatin for sepsis-associated acute respiratory distress syndrome. N Engl J Med. 2014;370(23):2191-200.

50. Papazian L, Roch A, Charles PE, Penot-Ragon C, Perrin G, Roulier P, et al. Effect of statin therapy on mortality in patients with ventilator-associated pneumonia: a randomized clinical trial. Jama. 2013;310(16):1692-700.

51. Hennessy E, Mooij MJ, Legendre C, Jerry Reen F, O'Callaghan J, Adams C, et al. Statins inhibit in vitro virulence phenotypes of Pseudomonas aeruginosa. The Journal of Antibiotics. 2013;66(2):99-101.

52. Li Y-H, Tian X. Quorum sensing and bacterial social interactions in biofilms. Sensors (Basel). 2012;12(3):2519-38. 53. Cruz CD, Shah S, Tammela P. Defining conditions for biofilm inhibition and eradication assays for Gram-positive clinical reference strains. BMC Microbiol. 2018;18(1):173-.

54. Waters EM, Rowe SE, O'Gara JP, Conlon BP. Convergence of Staphylococcus aureus Persister and Biofilm Research: Can Biofilms Be Defined as Communities of Adherent Persister Cells? PLoS Pathog. 2016;12(12):e1006012-e.

55. Björkhem-Bergman L, Lindh JD, Bergman P. What is a relevant statin concentration in cell experiments claiming pleiotropic effects? Br J Clin Pharmacol. 2011;72(1):164-5.

56. DeGorter MK, Tirona RG, Schwarz UI, Choi Y-H, Dresser GK, Suskin N, et al. Clinical and pharmacogenetic predictors of circulating atorvastatin and rosuvastatin concentrations in routine clinical care. Circ Cardiovasc Genet. 2013;6(4):400-8.

57. Inzana JA, Schwarz EM, Kates SL, Awad HA. Biomaterials approaches to treating implant-associated osteomyelitis. Biomaterials. 2016;81:58-71.

58. Mundy G, Garrett R, Harris S, Chan J, Chen D, Rossini G, et al. Stimulation of bone formation in vitro and in rodents by statins. Science (New York, NY). 1999;286(5446):1946-9.

59. Yoshii T, Hafeman AE, Nyman JS, Esparza JM, Shinomiya K, Spengler DM, et al. A sustained release of lovastatin from biodegradable, elastomeric polyurethane scaffolds for enhanced bone regeneration. Tissue engineering Part $A$. 2010;16(7):2369-79. 
60. Yoshii T, Hafeman AE, Esparza JM, Okawa A, Gutierrez G, Guelcher SA. Local injection of lovastatin in biodegradable polyurethane scaffolds enhances bone regeneration in a critical-sized segmental defect in rat femora. Journal of tissue engineering and regenerative medicine. 2014;8(8):589-95.

61. Istvan ES, Deisenhofer J. Structural mechanism for statin inhibition of HMG-CoA reductase. Science (New York, NY). 2001;292(5519):1160-4.

62. Wilding EI, Kim DY, Bryant AP, Gwynn MN, Lunsford RD, McDevitt D, et al. Essentiality, expression, and characterization of the class II 3-hydroxy-3-methylglutaryl coenzyme A reductase of Staphylococcus aureus. J Bacteriol. 2000;182(18):5147-52.

63. Zhang S, Rahman M, Zhang S, Qi Z, Thorlacius H. Simvastatin antagonizes CD40L secretion, CXC chemokine formation, and pulmonary infiltration of neutrophils in abdominal sepsis. Journal of leukocyte biology. 2011;89(5):73542.

64. Kothe H, Dalhoff K, Rupp J, Muller A, Kreuzer J, Maass M, et al. Hydroxymethylglutaryl coenzyme A reductase inhibitors modify the inflammatory response of human macrophages and endothelial cells infected with Chlamydia pneumoniae. Circulation. 2000;101(15):1760-3.

65. Ando H, Takamura T, Ota T, Nagai Y, Kobayashi K. Cerivastatin improves survival of mice with lipopolysaccharideinduced sepsis. The Journal of pharmacology and experimental therapeutics. 2000;294(3):1043-6.

66. Sanchez CJ, Mende K, Beckius ML, Akers KS, Romano DR, Wenke JC, et al. Biofilm formation by clinical isolates and the implications in chronic infections. BMC Infect Dis. 2013;13(1):47.

67. CLSI C. Performance standards for antimicrobial susceptibility testing. Clinical Lab Standards Institute. 2016.

68. Mackay ML, Milne K, Gould IM. Comparison of methods for assessing synergic antibiotic interactions. International Journal of Antimicrobial Agents. 2000;15(2):125-9. 


\section{Figure Legends}

Figure 1. Efficacy of rifampin, simvastatin, fluvastatin and mevastatin against established $S$. aureus UAMS-1 biofilm using the MBEC assay. UAMS-1 biofilm was established on polystryene pegs after $24 \mathrm{~h}$ of culture with TSB supplemented with $10 \%$ ( $\mathrm{vol} / \mathrm{vol}$ ) human plasma. Established biofilm was then challenged by 3 statins, simvastatin, fluvastatin, and mevastatin, and a rifamycin class of antibiotics, rifampin. Drugs were tested from concentrations 1 to $128 \mu \mathrm{g} / \mathrm{mL}$. All concentrations of rifampin significantly killed biofilm in comparison to all 3 statins. * indicates $P<0.05$; versus simvastatni, fluvastatin, or mevastatin at each of the respective concentrations by 2-way ANOVA with Sidak's multiple comparison test. $n=4-6 /$ group. Data represented as mean \pm standard error of the mean.

Figure 2. Evaluation of simvastatin against stationary phase $S$. aureus and persister cells. (a) Stationary phase cultures of UAMS-1 S. aureus were prepared by overnight cultures and incubated with $10 \times$ the MIC of gentamicin, rifampin, vancomycin, daptomycin, and simvastatin for 4 days. No antimicrobial was effective against the stationary phase population. (b) An overnight culture of UAMS-1 was adjusted to $1 \times 10^{8} \mathrm{CFU} / \mathrm{mL}$ and spiked with 10x MIC of gentamicin. At $24 \mathrm{~h}$, a second antimicrobial of either rifampin, simvastatin, or a retinoid antibiotic, CD437 was added. Only the proven retinoid antibiotic, CD437, was able to kill the surviving persister cell population. Data represented as means and \pm standard deviation.

Figure 3. Cytotoxicity of simvastatin, rifampin, and vancomycin against human osteoblasts. The average percent cell viability of human osteoblasts was categorized as viable (61-100\%), fairly viable (40-60\%), and cytotoxic $(<40 \%)$. (a) Simvastatin demonstrated viable to farily viability at concentrations ranging from 1 to 32 $\mu \mathrm{g} / \mathrm{mL}$. However, there was a drastic cytotoxic dropoff at all concentrations beyond $32 \mu \mathrm{g} / \mathrm{mL}$. (b) All concentrations of rifampin had minimal cytotoxicity with only the highest concentration tested, $512 \mu \mathrm{g} / \mathrm{mL}$, dropping to $60 \%$ viability. (c) Vancomycin demonstrated extremely favorable viability with all concentrations tested exceeding the cell viability of the mock-treated growth control. (d) Heat map summarizing the categorized viability of all concentrations for each drug. Numbers within the cells are percent viability (\%). All bars represented are means and error bars are \pm SEM. 
Data Tables

Table 1 - Minimum inhibitory concentrations of statins against pathogens associated with wound infections

Drug

Simvastatin

Pravastatin

Atorvastatin

Mevastatin

Cerivastatin

Pitavistatin

Lovastatin

Fluvastatin

Rosuvastatin

Drug

Simvastatin

Pravastatin

Atorvastatin

Mevastatin

Cerivastatin

Pitavistatin

Lovastatin

Fluvastatin

Rosuvastatin

Drug

Simvastatin

Pravastatin

Atorvastatin

Mevastatin

Cerivastatin

Pitavistatin

Lovastatin

Fluvastatin

Rosuvastatin
Staphylococcus aureus $(\mathrm{n}=5)$ MIC (range, $\mu \mathrm{g} / \mathrm{mL}$ )

32 (64-32)

256 (64-256)

$64(32-128)$

$256(>256)$

256 (128-256)

$256(128-256)$

256 (>256)

$64(16-256)$

256 (>256)

Coagulase-negative

staphylococcus $(n=5)$

MIC (range, $\mu \mathrm{g} / \mathrm{mL}$ )

32 (8-64)

$256(>256)$

256 (64->256)

256 (>256)

$256(128-256)$

256 (64-256)

256 (>256)

$256(128-256)$

$256(>256)$

Klebsiella spp $(\mathrm{n}=5)$

MIC (range, $\mu \mathrm{g} / \mathrm{mL}$ )

256 (>256)

256 (>256)

$256(>256)$

$256(>256)$

$256(>256)$

$256(>256)$

256 (>256)

$256(>256)$

$256(>256)$
Pseudomonas aeruginosa $(\mathrm{n}=5)$

$32(16-256)$

$256(>256)$

$256(>256)$

$256(>256)$

$256(>256)$

$256(>256)$

$256(>256)$

$256(>256)$

$256(>256)$

Escherichia coli $(\mathrm{n}=5)$

$256(>256)$

$256(>256)$

$256(>256)$

$256(>256)$

$256(>256)$

$256(>256)$

$256(>256)$

$256(>256)$

$256(>256)$

Acinetobacter baumannii $(\mathrm{n}=5)$

32 (8-256)

64 (64-256)

$64(16-256)$

$128(64-256)$

$64(32-256)$

$64(8-256)$

$64(8-256)$

$128(16-256)$

$64(16-256)$ 
672 Table 2 - Minimum biofilm inhibition concentration (MBIC) of statins against $S$. aureus, coagulase-negative 673 staphylococcus (CoNS), and $A$. baumannii

\begin{tabular}{|l|l|l|l|}
\hline Drug & $\begin{array}{l}\text { Staphylococcus } \\
\text { aureus }(\mathbf{n}=5)\end{array}$ & \multicolumn{1}{|l|}{$\begin{array}{l}\text { Coagulase-negative } \\
\text { staphylococcus }(\mathbf{n}=5)\end{array}$} & $\begin{array}{l}\text { Acinetobacter } \\
\text { baumannii }(\mathbf{n}=5)\end{array}$ \\
\hline Simvastatin & $8(1-128)$ & $8(4-64)$ & $256(128-256)$ \\
\hline Pravastatin & $32(8-256)$ & $128(8-256)$ & $256(>256)$ \\
\hline Atorvastatin & $128(4-256)$ & $256(32-256)$ & $256(128-256)$ \\
\hline Mevastatin & $4(1-8)$ & $256(>256)$ & $256(16-256)$ \\
\hline Cerivastatin & $64(4-256)$ & $64(4-256)$ & $256(128-256)$ \\
\hline Pitavistatin & $256(16-256)$ & $256(16-256)$ & $256(128-256)$ \\
\hline Lovastatin & $256(16-256)$ & $64(16-256)$ & $256(>256)$ \\
\hline Fluvastatin & $8(2-256)$ & $256(16-256)$ & $256(16-256)$ \\
\hline Rosuvastatin $8(4-128)$ & $256(>256)$ & $256(>256)$ \\
\hline
\end{tabular}


Table 3 - Minimum inhibitory concentrations (MIC) of select statins and antibiotics against $S$. aureus strains UAMS- 1 and USA300

\begin{tabular}{|l|l|l|}
\hline Drug & $32 \mu \mathrm{g} / \mathrm{mL}$ & $32 \mu \mathrm{g} / \mathrm{mL}$ \\
\hline Simvastatin & $128 \mu \mathrm{g} / \mathrm{mL}$ & $128 \mu \mathrm{g} / \mathrm{mL}$ \\
\hline Fluvastatin & $256 \mu \mathrm{g} / \mathrm{mL}$ & $256 \mu \mathrm{g} / \mathrm{mL}$ \\
\hline Mevastatin & $256 \mu \mathrm{g} / \mathrm{mL}$ & $256 \mu \mathrm{g} / \mathrm{mL}$ \\
\hline Rosuvastatin & $0.5 \mu \mathrm{g} / \mathrm{mL}$ & $0.5 \mu \mathrm{g} / \mathrm{mL}$ \\
\hline Tobramycin & $0.5 \mu \mathrm{g} / \mathrm{mL}$ & $0.5 \mu \mathrm{g} / \mathrm{mL}$ \\
\hline Gentamicin & $1 \mu \mathrm{g} / \mathrm{mL}$ & $1 \mu \mathrm{g} / \mathrm{mL}$ \\
\hline Vancomycin & & $0.004 \mu \mathrm{g} / \mathrm{mL}$ \\
\hline Rifampin & $0.004 \mu \mathrm{g} / \mathrm{mL}$ & \\
\hline
\end{tabular}


Table 4 - Simvastatin mode of action for various concentrations relative to minimum inhibitory concentration (MIC)

\begin{tabular}{|l|l|}
\hline Concentration of Simvastatin & Mode Of Action \\
\hline $8 \mathrm{X}$ MIC & Bacteriostatic \\
\hline $4 \mathrm{X}$ MIC & Bacteriostatic \\
\hline $2 \mathrm{X}$ MIC & Bacteriostatic \\
\hline $1 \mathrm{X} \mathrm{MIC}$ & Bacteriostatic \\
\hline $1 / 2 \mathrm{X} \mathrm{MIC} \mathrm{(Growth} \mathrm{Control)}$ & Bacterial Growth \\
\hline
\end{tabular}


681 Table 5 - Fractional inhibitory concentration (FIC) to determine synergy of simvastatin with select antibiotics

\begin{tabular}{|l|l|l|l|l|}
\cline { 2 - 5 } \multicolumn{2}{l|}{} & \multicolumn{2}{l|}{ UAMS-1 } & USA300 \\
\hline Drug & FIC & Effect & FIC & Effect \\
\hline Tobramycin & 0.8437 & Additive & 1.208 & Indifferent \\
\hline Gentamicin & 0.9187 & Additive & 0.57 & Additive \\
\hline Vancomycin & 2 & & & Indifferent \\
\hline Rifampin & 1.25 & Indifferent & 1.5 & Indifferent \\
\hline
\end{tabular}

682 Note: Synergistic FIC $\leq 0.5$, Additive FIC = 0.5-1.0, Indifferent FIC = 1.0-4.0, Antagonistic FIC > 4.0 
684 Table 6 - Minimum Biofilm Eradication Concentration (MBEC) for established UAMS-1 S. aureus biofilm

685

\begin{tabular}{|l|c|}
\hline Drug & MBEC $(\boldsymbol{\mu g} / \mathbf{m L})$ \\
\hline Rifampin & 16 \\
\hline Fluvastatin & $>512$ \\
\hline Mevastatin & $>512$ \\
\hline Simvastatin & $>512$ \\
\hline
\end{tabular}






\section{$\square$ Rifampin $\square$ Simvastatin $\square$ Fluvastatin $\square$ Mevastatin}

Figure 1. Efficacy of rifampin, simvastatin, fluvastatin and mevastatin against established S. aureus UAMS-1 biofilm using the MBEC assay. UAMS-1 biofilm was established on polystryene pegs after $24 \mathrm{~h}$ of culture with TSB supplemented with $10 \%$ (vol/vol) human plasma. Established biofilm was then challenged by 3 statins, simvastatin, fluvastatin, and mevastatin, and a rifamycin class of antibiotics, rifampin. Drugs were tested from concentrations 1 to $128 \mu \mathrm{g} / \mathrm{mL}$. All concentrations of rifampin significantly killed biofilm in comparison to all 3 statins. * indicates $P<0.05$ versus simvastatin, fluvastatin, or mevastatin at each of the respective concentrations by 2 -way ANOVA with Sidak's multiple comparison test. $n=4-8 /$ group. Data represented as mean \pm standard error of the mean (SEM). 
a

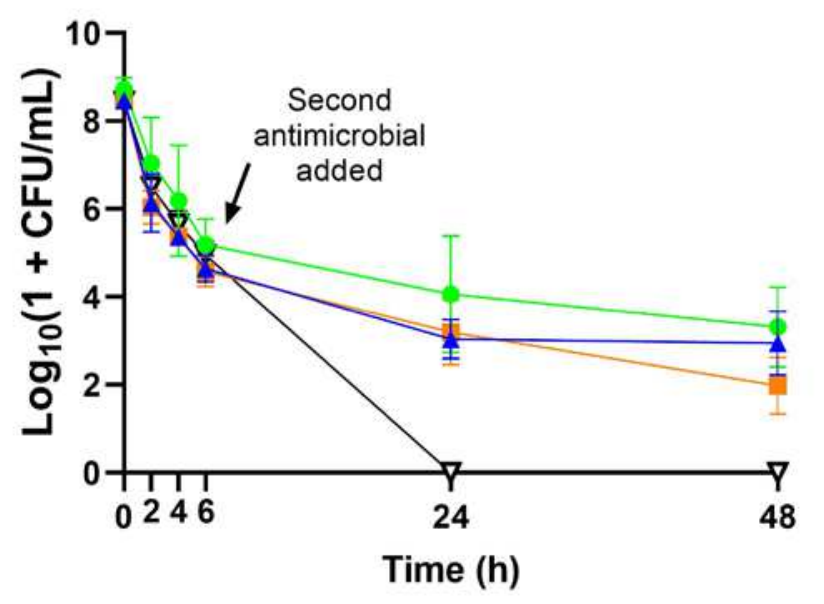

$\rightarrow$ Gentamicin Gentamacin then Rifampin

$\star$ Gentamicin then Simvastatin $\rightarrow-$ Gentamicin + CD437 b

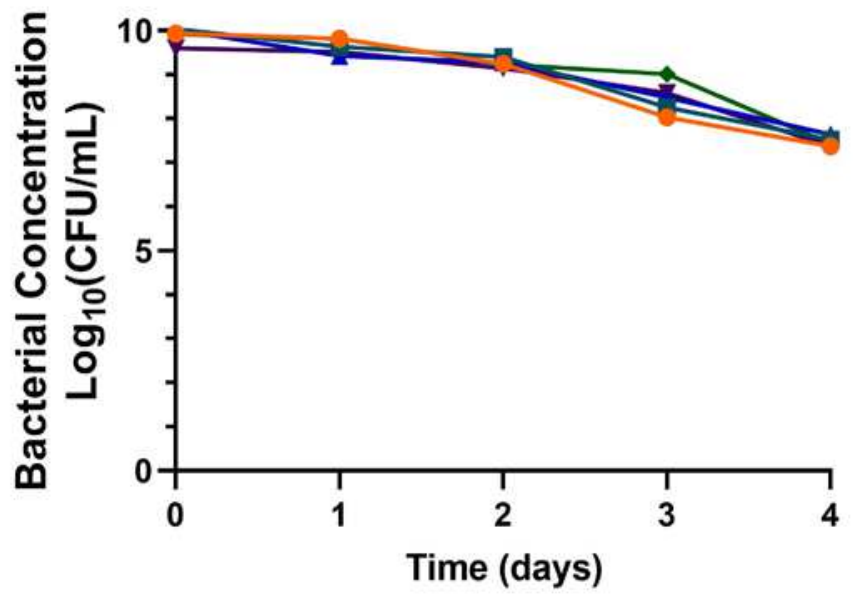

$\rightarrow$ Growth Control $\rightarrow$ Rifampin $\rightarrow$ - Vancomycin

$\rightarrow$ Daptomycin $\leftarrow$ Simvastatin

Figure 2. Evaluation of simvastatin against stationary phase $S$. aureus and persister cells. (a) Stationary phase cultures of UAMS-1 S. aureus were prepared by overnight cultures and incubated with $10 \times$ the MIC of gentamicin, rifampin, vancomycin, daptomycin, and simvastatin for 4 days. No antimicrobial was effective against the stationary phase population. (b) An overnight culture of UAMS-1 was adjusted to $1 \times 10^{8} \mathrm{CFU} / \mathrm{mL}$ and spiked with $10 \times$ MIC of gentamicin. At $24 \mathrm{~h}$, a second antimicrobial of either rifampin, simvastatin, or a retinoid antibiotic, CD437 was added. Only the proven retinoid antibiotic, CD437, was able to kill the surviving persister cell population. Data represented as means and \pm standard deviation. 
a.

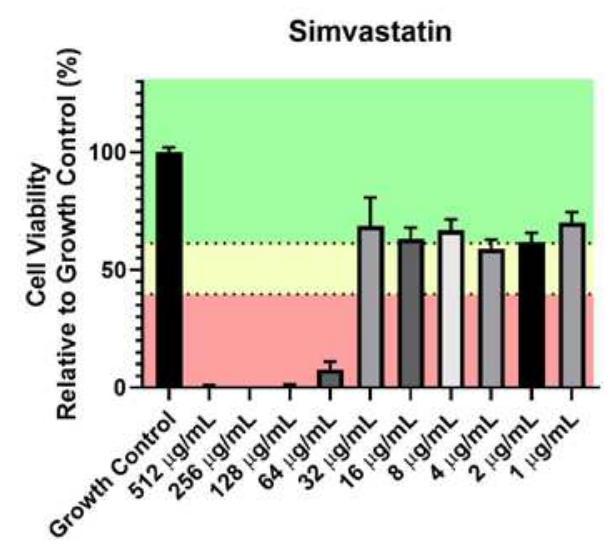

b.

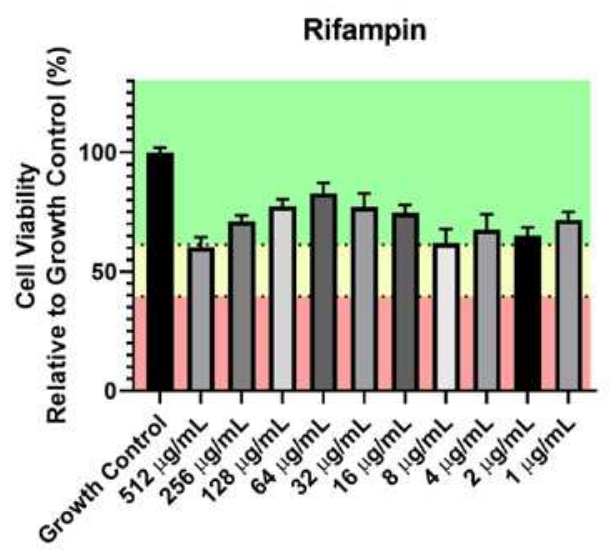

c.

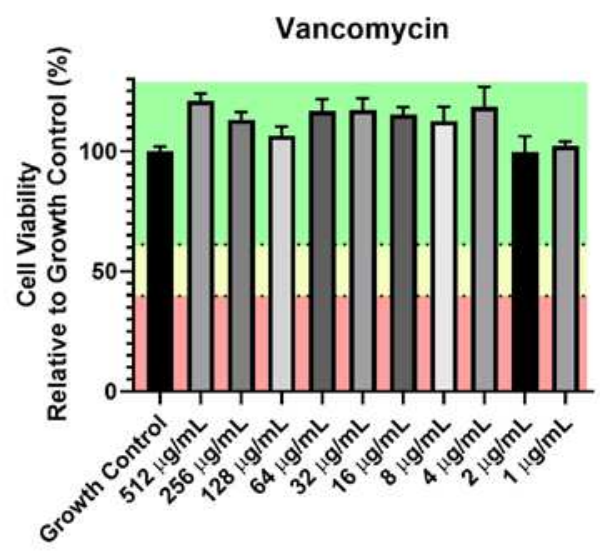

d.

\begin{tabular}{|c|c|c|c|c|c|c|c|c|c|c|}
\hline & & & & & & 32 & 64 & 128 & 256 & \\
\hline \multirow{3}{*}{$\begin{array}{l}\text { Sim vastatin } \\
\text { Rifampin } \\
\text { Vancomycin }\end{array}$} & 70 & 62 & 59 & 67 & 63 & 69 & 8 & 0 & 0 & 0 \\
\hline & 72 & 65 & 68 & 62 & 75 & 77 & 82 & 77 & 71 & 60 \\
\hline & 102 & 100 & 118 & 113 & 115 & 117 & 117 & 106 & 113 & 121 \\
\hline
\end{tabular}

Cell viability relative to growth control (\%)

$61-100$

$40-60$ $<40$

Figure 3. Cytotoxicity of simvastatin, rifampin, and vancomycin against human osteoblasts. The average percent cell viability of human osteoblasts was categorized as viable (61-100\%), fairly viable (40-60\%), and cytotoxic $(<40 \%)$. (a) Simvastatin demonstrated viable to farily viability at concentrations ranging from 1 to 32 $\mu \mathrm{g} / \mathrm{mL}$. However, there was a drastic cytotoxic dropoff at all concentrations beyond $32 \mu \mathrm{g} / \mathrm{mL}$. (b) All concentrations of rifampin had minimal cytotoxicity with only the highest concentration tested, $512 \mu \mathrm{g} / \mathrm{mL}$, dropping to $60 \%$ viability. (c) Vancomycin demonstrated extremely favorable viability with all concentrations tested exceeding the cell viability of the mock-treated growth control. (d) Heat map summarizing the categorized viability of all concentrations for each drug. Numbers within the cells are percent viability (\%). All bars represented are means and error bars are \pm SEM. 